\title{
Integration of family planning services with HIV treatment for women of reproductive age attending ART clinic in Oromia regional state, Ethiopia
}

\author{
Dereje Bayissa Demissie ${ }^{1,2^{*}}$ and Rose Mmusi-Phetoe ${ }^{3}$
}

\begin{abstract}
Background: In settings where HIV prevalence is high, management of sexual and reproductive health is critical to reducing HIV transmission and maternal mortality. Integration of family planning with HIV services is appropriate for HIV therapy, HIV prevention, and care in a resource-limited country s like Ethiopia. The study aimed at examining the status of integration of family planning services with HIV treatment and factors associated with successful integration of family planning and HIV services for women of reproductive age in Oromia, Ethiopia for better health outcomes.
\end{abstract}

Methods: The research design of this study was a quantitative survey, non-experimental, explorative and descriptive. A questionnaire was used to collect data from women living with HIV attending ART clinics in the special zone of surrounding Finfinne, Oromia Region in five health centers. Simple random sampling was used to select 654 respondents. Data was analysed through the use of Statistical Package for Social Sciences version 23.0. Bivariate and multivariate logistic regressions were performed to identify factors associated integration of family planning with HIV services with the significant association at an adjusted odds ratio (AOR) with a 95\% confidence interval (CI) to controlled effects of possible confounders from the final model.

Result: The response rate of this study was $97.6 \%$ (654/670). The ages of those who responded to the administered questionnaires ranged between 18 and 49 years. The mean age of the respondents was 31.86 years with an SD of \pm 6.0 years. Most of the respondents in the sample were in the age group $26-35(n=374,57 \%)$, and only $96(14.7 \%)$ were in the age group 18-25. This overall integration of FP-HIV services among reproductive-age women living with HIV in Oromia regional state of special zone health centers was found to be $55.8 \%$. Almost all respondents $(n=635$, 97.1\%) preferred integrated family planning and HIV services from the same facility and the same providers. the study found that 622 (95\%) were most satisfied with the utilization of integrated family planning/HIV services.

Conclusion: This study established that in overall, the integration of family planning/HIV services was relatively moderate among women of reproductive age living HIV. The identified factors that affected the integration of family planning with HIV services were the level of education, occupational status, residence, discussion of family planning with healthcare providers, fertility desire and CD4 counts.

*Correspondence: dereje.bayissa@sphmmc.edu.et

${ }^{1}$ Department of Health Studies, College of Human Science, University

of South Africa, Pretoria, South Africa

Full list of author information is available at the end of the article

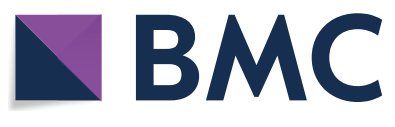

(c) The Author(s) 2021. Open Access This article is licensed under a Creative Commons Attribution 4.0 International License, which permits use, sharing, adaptation, distribution and reproduction in any medium or format, as long as you give appropriate credit to the original author(s) and the source, provide a link to the Creative Commons licence, and indicate if changes were made. The images or other third party material in this article are included in the article's Creative Commons licence, unless indicated otherwise in a credit line to the material. If material is not included in the article's Creative Commons licence and your intended use is not permitted by statutory regulation or exceeds the permitted use, you will need to obtain permission directly from the copyright holder. To view a copy of this licence, visit http://creativecommons.org/licenses/by/4.0/. The Creative Commons Public Domain Dedication waiver (http://creativeco mmons.org/publicdomain/zero/1.0/) applies to the data made available in this article, unless otherwise stated in a credit line to the data. 


\section{Plain language summary}

These study findings are strongly in favour of integrated services offering multiple health services at the same facility by the same provider. Service integration based on the needs of women of reproductive age was found to be necessary in public health facilities where people have access only to primary healthcare facilities.

Integrated family planning with HIV (FP-HIV) services contribute to women's wellbeing by addressing a wide range of health needs and offering convenience of receiving multiple services a single visit. Integrated FP-HIV services further address women's vulnerability to other sexual reproductive health problems.

Integrated FP-HIV services should contribute to comprehensive national family planning programs to enable the provision of full access to a variety of contraceptive methods. The latter should enable couples and individuals to obtain services at a one-stop supermarket to achieve optimal reproductive and sexual health to meet their needs.

The findings from study generated adequate knowledge and equipped managers with skills integrating family planning with HIV services among women of reproductive age in Oromia regional state, Ethiopia.

The study's findings have emphasized the urgent need to fully implement action focusing on integrating family planning/HIV services for women of reproductive age living HIV and attending ART clinics. The study prioritized the need to strengthen the capacity of health centers to provide quality FP-HIV.

Keywords: Family planning, HIV services, Integration, Women living with HIV

\section{Introduction}

The integration of 'family planning with human immune-deficiency virus (HIV) services to promote contraceptive use among "women living with HIV" has emerged as a rich ground for research. Integrating family planning and HIV services is a process that occurs at different levels of the health care system such as national, regional, district, and health facility levels for effective functioning of key functions such as governance, financing, planning, service delivery, monitoring, evaluation, and demand generation [1].

In this study, integration family planning with HIV treatment means linking these programs by offering one-stop comprehensive at a healthcare facility [2].

According to WHO [3] member countries should ensure universal access to sexual and reproductive healthcare services, including family planning, information and education, and the integration of reproductive health into national strategies and programs by the end of 2030 [3, 4]. According to a study by [5], integration of health service delivery is key to addressing improvements in $\mathrm{MNCH}$ services and HIV care and treatment in sub-Saharan African countries. Public health programs emphasize that the integration of family planning services with HIV treatment to increases dual contraceptive methods' utilization will ensure protection from both unintended pregnancy and STIs, including HIV/AIDS [6].

\section{Statement of the problems}

In 2012 it was estimated that in sub-Saharan Africa, 53 million women who wanted to avoid pregnancy were not using any family planning method [7]. Sarnquist et al. [8] add that an unmet need for contraception among women living with HIV in sub-Saharan Africa is high, with $66-92 \%$ of women reporting not wanting another child (now or ever). Only $20-43 \%$ of these women were using contraception. The prevalence of unmet needs for family planning thus remains unacceptably high among women in sub-Saharan Africa, including those living with HIV, even if they are involved in HIV treatment programs [7, 8].

According to the 'Ethiopia Demographic and Health Survey' (EDHS) of 2016, 28.9\% of currently married women in the Oromia Region have an unmet need for family planning services; $17.1 \%$ for spacing, $11.8 \%$ for limiting, and only $28.6 \%$ women have received family planning services. The total demand for family planning in Oromia Region was 57.55\% [9].

Meeting the unmet needs for family planning in subSaharan Africa could make an important contribution to improving maternal health through early studies 2008 , the estimated maternal mortality ratio in subSaharan Africa was 596 per 100,000 live births, the contraceptive prevalence was $22 \%$, and the proportion of maternal deaths averted by contraceptive use was estimated at $32 \%$. In contrast, among low-and-middle-income countries as a group, the maternal mortality ratio was 273 , the contraceptive prevalence was $63 \%$, and $44 \%$ of maternal deaths were estimated to be averted by family planning use [10].

Programs that have succeeded in promoting condom use and providing HIV prevention and treatment services in this region have largely missed the opportunity to address the contraceptive needs of the key populations 
they serve. Therefore, the research statement for this study what is the status of the integration between family planning and HIV treatment services for women of reproductive age living with HIV attending healthcare facilities in the Oromia Region, Ethiopia?

\section{Methods and materials}

\section{Research setting and design}

This study was conducted in the Oromia Region surroundings of Finfinne Oromia, Ethiopia. Currently, the health system of the zone consists of two hospitals under construction, and 27 health centers with $98 \%$ potential health service coverage. There were different governmental and non-governmental organizations working on HIV/AIDS in the zone. 13 health centers have been providing ART and family planning services in the zone, of which five were randomly selected as the study setting. The total number of people living with HIV enrolled at ART clinics in the zone was 9421 , of which 2380 were women of reproductive age, and of these, 1557 were from five randomly selected health centers [11]. The target population was HIV-positive women of reproductive age who had attended ART follow-up services for at least six months from randomly selected healthcare facilities in the Oromia Region, Ethiopia. The accessible sample was 1557 eligible women of reproductive age living with HIV attending ART clinics in public health centers.

A quantitative survey, non-experimental, explorative, and descriptive. A questionnaire was used to collect data from women living with HIV attending ART clinics.

\section{Sample size determination}

The sample size was determined by using single population proportion formula with the assumption that $40 \%$ proportion $(\mathrm{P})$ of women of reproductive age living HIV have utilized family planning at integrated sites of Health facility in Ethiopia [12] at a 5\% level of significance and a margin of error of $5 \%$. By considering the design effect of 2 , with correction formula since the total population was less than 10,000 (2380) and with a 5\% non-response rate considered, the final sample size was 670 women living with HIV.

\section{Sampling procedure}

All hospitals and health centers found in the Special Zone of Oromia Region that provide ART services were identified and randomly selected by computer-generated methods by using SPSS version 23.0 software application to be included in the study. Study sites were prepared and entered into SPSS version 23 by using their pre-ART registration numbers from the health management information system (HMIS) database. A list of all women living with HIV from each facility, aged between 18 and
49 years of age, was randomly created. Simple random computer-generated sampling was utilized at each health center to select 670 study respondents. The number of study respondents was allocated proportionally for the five health centers, based on their total number of ART clients.

\section{Data collection}

The questionnaire used for data collection was initially prepared in English, and translated to Afan Oromo, and back to English for language experts to confirm its consistency. Finally, the corrected Afan Oromo version was used to collect the data from women living with HIV attending ART clinics. The questions included in the questionnaire were adapted and prepared by reviewing different related literature and variables identified to be measured. The training was given to data collectors and supervisors by the primary researcher for two days. Data collectors cross-checked the pre-ART card numbers of women living with HIV who came to the ART clinic with sampled card numbers daily. Five trained data collectors collected data from women of reproductive age. The completed questionnaires were collected and checked daily for consistency and completeness by supervisors and the primary researcher. Data were collected using a pre-tested structured Afan Oromo version of the questionnaire. A pre-test of the questionnaire was done on $5 \%$ of the women living with HIV at Ambo health center, to identify any ambiguity, to confirm consistency in the questionnaire, to determine acceptability, and to make necessary corrections one week before the actual data collection process. The respondents were guided through a questionnaire and chart abstraction conducted at their health facility by trained data collectors.

\section{Operational definition}

Integration of family planning with HIV treatment is offered at the same facility during the same operating hours, and the provider of one service encourages clients to consider using the other service during that visit which implies the possibility of more than one location within the facility and more than one service provider. In this study, integration of family planning with HIV treatment means that organizing these program by offering one-stop comprehensive and integrated services at ART Room [2]. The study objective of this to examine the status of integration of family planning services with HIV treatment for women of reproductive age in Oromia, Ethiopia.

The ten measurement variables related to integrating family planning/HIV services were analyzed through SPSS under data transform count the occurrence of a 
value in terms of the respondents who answered "yes" to the integration of family planning/HIV services.

\section{Data management and analysis}

The returned questionnaires were checked for completeness, cleaned manually, coded and entered into EPI INFO 7.1.6 version, and then transferred to SPSS version 23 for further analysis. Frequencies, percentages, mean and standard deviation (SD) were used to summarise descriptive statistics of the data and text. Moreover, tables and graphs will be used for data presentation. Bivariate analysis was used primarily to check which variables have an individual association with the dependent variable. In this analysis, the outcome variables, integrated family planning/HIV services, were dichotomized with "1" being integrated and "0" not integrated. Two different models were employed to investigate the factors predicting integration of family planning/HIV services. Accordingly, the Hosmer-Lemeshow Test (HL) for the two models showed chi-square p-values $>0.05$, which proved the goodness-of-fit of the applied models for this study at $\mathrm{p}=0.56$ for the integrated family planning/HIV services model.

The estimates of the crude and adjusted odds ratio (AOR) were fairly similar and this showed that the variables used for adjustment were not confounding variables [13]. Variables that were found to have an association with the dependent variables were then entered into multiple logistic regressions to control the possible effect of confounders. Finally, the variables which have significant association were identified based on AOR, with a 95\% CI and p-value to fit into the final regression model.

\section{Results}

\section{Response rate}

The response rate is the number of participants who completed a questionnaire, after 16 spoiled questionnaires were discarded. The study achieved a response rate of $97.6 \% 654 / 670$. The latter reflects the quality of training provided to interviewers, their understanding, and the daily supervision by the principal investigator.

There were 654 respondents whose ages ranged between 18 and 49 years. The mean age of the respondents was 31.86 years with an SD of \pm 6.0 years. Most of the respondents in the sample were in the age group $26-35(\mathrm{n}=374,57 \%)$ as reflected in Table 1 .

Table 1 presented the education status of the respondents which revealed that the literacy proportion was 409 $(62.5 \%)$. The majority $(n=409,62.5 \%)$ of the respondents had at least attended school from primary level to college/university level, and the least represented were $19(2.9 \%)$ who had attained tertiary level education in the form of attending a college or university. In terms of religious affiliation, 474(72.5\%) respondents belonged to the orthodox denomination,

Of the 609 (93.1\%) employed respondents, 256 (39.1\%) were housewives. These were followed by 239 (36.5\%) who were in the private or merchant sector, 55 (8.4\%) were self-employed in agriculture on their farms, and only $59(9.0 \%)$ were working for the public service sector. The family's monthly income distribution among the respondents was assessed, and it was found that on average, the income was 1398.18 Ethiopian Birr (50\$), and ranged from 100 to 5000. More than 357 (54.6\%) respondents were earning less than 1201 Ethiopian birr $(1 \$=27.84$ Birr $)$.

\section{Integrating family planning with HIV services}

On assessing the level of integrated family planning with HIV services in the ART clinics, this study found that the ART providers provided a contraceptive method mix in ART clinics, of which $93.7 \%$ were condoms, $90.2 \%$ were injectable and $82.3 \%$ were oral contraceptives as chosen methods available during the study period. Therefore, the family planning/HIV services were integrated with the ART clinics of the Oromia Region and specifically focused on offering counseling on available family planning services to providing injectable contraceptive methods, pills, and condoms in the ART clinics. The integrated family planning/HIV services also referred women of reproductive age for consultation on available longacting reversible and permanent methods within the same facility.

Of the total number of respondents, 355 (54.3\%) received family planning counseling on available contraceptive methods by trained health professionals in the waiting room. Moreover, 548 (83.8\%) had attended family planning health education sessions in service settings offering ART, PMTCT, STI, VCT, and tuberculosis services. Of the total number of women of reproductive age living with HIV, 506 (77.4\%) had received family planning counseling on the efficacy of each method, its side effects, and method mix available in addition to ART services. Based on the counseling mentioned, a notable number of women living with HIV were referred for consultation at the family planning unit within the same facility on available long-acting and permanent contraceptive methods. The study revealed that 450 (68.8\%) were referred for implants, $401(61.3 \%)$ for an IUD, and $190(29.1 \%)$ for tubal ligation. The study further revealed that 548 (83.8\%) women living with HIV had received dual protection information during counseling, of which 337 (51.5\%) accepted dual method contraceptives from ART providers to prevent both unintended pregnancy and HIV transmission. 
Table 1 Demographic and socioeconomic characteristics of respondents in Oromia Region, Ethiopia $2018(\mathrm{~N}=654)$

\begin{tabular}{|c|c|c|c|}
\hline Demographic and social characteristics & Category & Frequency (\%) & Cumulative (\%) \\
\hline \multirow[t]{3}{*}{ Age in year $(n=654)$ Mean (SD): $31.86( \pm 6.0)$} & $18-25$ & $96(14.7)$ & 14.7 \\
\hline & $26-35$ & $374(57.2)$ & 71.9 \\
\hline & $36-49$ & $184(28.1)$ & 100.0 \\
\hline \multirow[t]{5}{*}{ Ethnic group } & Oromo & $460(70.3)$ & 70.3 \\
\hline & Amhara & $155(23.7)$ & 94.0 \\
\hline & Tigre & $10(1.5)$ & 95.6 \\
\hline & Gurage & $26(4.0)$ & 99.5 \\
\hline & Others (Wolayita, sidama) & $3(0.5)$ & 100.0 \\
\hline \multirow[t]{4}{*}{ Highest level of education } & Never been school & $245(37.5)$ & 37.5 \\
\hline & Primary & $284(43.4)$ & 80.9 \\
\hline & Secondary & $106(16.2)$ & 97.1 \\
\hline & College/university & $19(2.9)$ & 100.0 \\
\hline \multirow[t]{5}{*}{ Marital status } & Married & $528(80.7)$ & 80.7 \\
\hline & Cohabit/living together & $51(7.8)$ & 88.5 \\
\hline & Divorced/separated & $46(7.0)$ & 95.6 \\
\hline & Widowed & $22(3.4)$ & 98.9 \\
\hline & Single & $7(1.1)$ & 100.0 \\
\hline \multirow[t]{4}{*}{ Religious affiliation } & Orthodox & $474(72.5)$ & 72.5 \\
\hline & Protestant & $131(20.0)$ & 92.5 \\
\hline & Muslim & $42(6.4)$ & 98.9 \\
\hline & Catholic & $7(1.1)$ & 100.0 \\
\hline \multirow{4}{*}{$\begin{array}{l}\text { Family monthly income } \\
(1 \$=27.84 \text { Birr })\end{array}$} & $<=800$ Ethiopia Birr & $166(25.4)$ & 25.4 \\
\hline & 801-1200 Ethiopia Birr & $191(29.2)$ & 54.6 \\
\hline & 1201-1800 Ethiopia Birr & $136(20.8)$ & 75.4 \\
\hline & 1801 + Ethiopia Birr & $161(24.6)$ & 100.0 \\
\hline \multirow[t]{5}{*}{ Employment status } & Government employee & $59(9.0)$ & 9.0 \\
\hline & Merchant/private work & $239(36.5)$ & 45.6 \\
\hline & Housewife & $256(39.1)$ & 84.7 \\
\hline & Farmers & $55(8.4)$ & 93.1 \\
\hline & Unemployed & $45(6.9)$ & 100.0 \\
\hline \multirow[t]{2}{*}{ Residence } & Urban & $518(79.2)$ & 79.2 \\
\hline & Rural & $136(20.8)$ & 100.0 \\
\hline
\end{tabular}

Table 3 depicts that 422 (64.5\%) women living with HIV who were attending ART were screened, counseled, and provided with injectable contraceptives, and $151(23.1 \%)$ received an implant during their ART drug refilling at the clinic.

Of the respondents, 616 (94.2\%) mentioned that service providers were knowledgeable and comfortable in providing integrated family planning/HIV counseling, and $537(82.1 \%)$ stated that service providers were knowledgeable and comfortable providing integrated family planning/HIV services. Table 2.

The overall integration of family planning/HIV services was reported by 365 (55.8\%) of 654 respondents, which ranges from 51.8 to $59.5 \%$ with $95 \%$ CI (Fig. 1).
Figure 2 reveals that as integrated family planning/HIV services increased, the number of modern contraceptive utilisers also increased. It was discovered that 325 (50\%) current family planning users were using integrated family planning/HIV services versus 40 (6.1\%) who were not using integrated services (Fig. 2).

This study determined that the integration of family planning with HIV services ranged from counseling on family planning in the ART room to the provision of injectable contraceptive methods. Moreover, it also entailed patients being referred to a family planning unit in the same facility for long-acting and permanent contraceptive methods. An exit interview was conducted to determine the level of satisfaction on the utilization of integrated services, as briefly exhibited in Fig. 3. The 
Table 2 Integration of family planning/HIV services of health Centres in Oromia Region, Ethiopia 2018

\begin{tabular}{|c|c|c|c|}
\hline Level of integration of family planning/HIV services & Categories & Frequency (\%) & \\
\hline \multirow[t]{2}{*}{ Receipt of family planning counselling in the waiting room } & Yes & $355(54.3)$ & \\
\hline & No & $299(45.7)$ & \\
\hline \multirow[t]{4}{*}{ Choice of contraceptive methods in need of available methods } & & Yes & No \\
\hline & Injectable & $590(90.2)$ & $64(9.8)$ \\
\hline & Condoms & $613(93.7)$ & $41(6.3)$ \\
\hline & Oral contraceptives & $538(82.3)$ & $116(17.7)$ \\
\hline \multirow{4}{*}{ Referral of clients for consultation of on available long-acting and permanent methods } & Implants & $450(68.8)$ & $204(31.2)$ \\
\hline & Intrauterine device (IUD) & $401(61.3)$ & $253(38.7)$ \\
\hline & Tubal ligation & $190(29.1)$ & $464(70.9)$ \\
\hline & Vasectomy & $167(25.5)$ & $487(74.5)$ \\
\hline \multirow{2}{*}{\multicolumn{2}{|c|}{ Counselling about each method efficacy, side effects and available contraception mix in addition to ART services }} & Yes & $506(77.4)$ \\
\hline & & No & $148(22.6)$ \\
\hline \multirow{2}{*}{\multicolumn{2}{|c|}{$\begin{array}{l}\text { Attended family planning health education sessions in service settings offering ART, PMTCT, STI, VCT and tuberculo- } \\
\text { sis services }\end{array}$}} & Yes & $249(38.1)$ \\
\hline & & No & $405(61.9)$ \\
\hline \multirow{2}{*}{\multicolumn{2}{|c|}{ Information provided on dual protection during ART drug refill in the ART room }} & Yes & $548(83.8)$ \\
\hline & & No & $106(16.2)$ \\
\hline \multirow{2}{*}{\multicolumn{2}{|c|}{ Dual method contraceptive provided for prevention of both unintended pregnancy and HIV transmission }} & Yes & $337(51.5)$ \\
\hline & & No & $211(32.3)$ \\
\hline \multirow{2}{*}{\multicolumn{2}{|c|}{ Screening, counselling and provided injectable family planning in the ART room }} & Yes & $422(64.5)$ \\
\hline & & No & $232(35.5)$ \\
\hline \multirow{2}{*}{\multicolumn{2}{|c|}{ Screening, counselling and provided implant for clients in the ART room }} & Yes & $151(23.1)$ \\
\hline & & No & $503(76.9)$ \\
\hline \multirow{2}{*}{\multicolumn{2}{|c|}{ provided instructions of IUD or implant, including recommended date of removal provided }} & Yes & $412(63.0)$ \\
\hline & & No & $242(37.0)$ \\
\hline \multirow{2}{*}{\multicolumn{2}{|c|}{ Counselling offered for informed decision-making and consent for permanent methods }} & Yes & $524(80.1)$ \\
\hline & & No & $130(19.9)$ \\
\hline \multirow{2}{*}{\multicolumn{2}{|c|}{ Service providers knowledgeable and comfortable with providing integrated family planning/HIV counselling }} & Yes & $616(94.2)$ \\
\hline & & No & $38(5.8)$ \\
\hline \multirow{2}{*}{\multicolumn{2}{|c|}{ Service providers knowledgeable and comfortable with providing integrated family planning/HIV services }} & Yes & $537(82.1)$ \\
\hline & & No & $117(17.9)$ \\
\hline
\end{tabular}

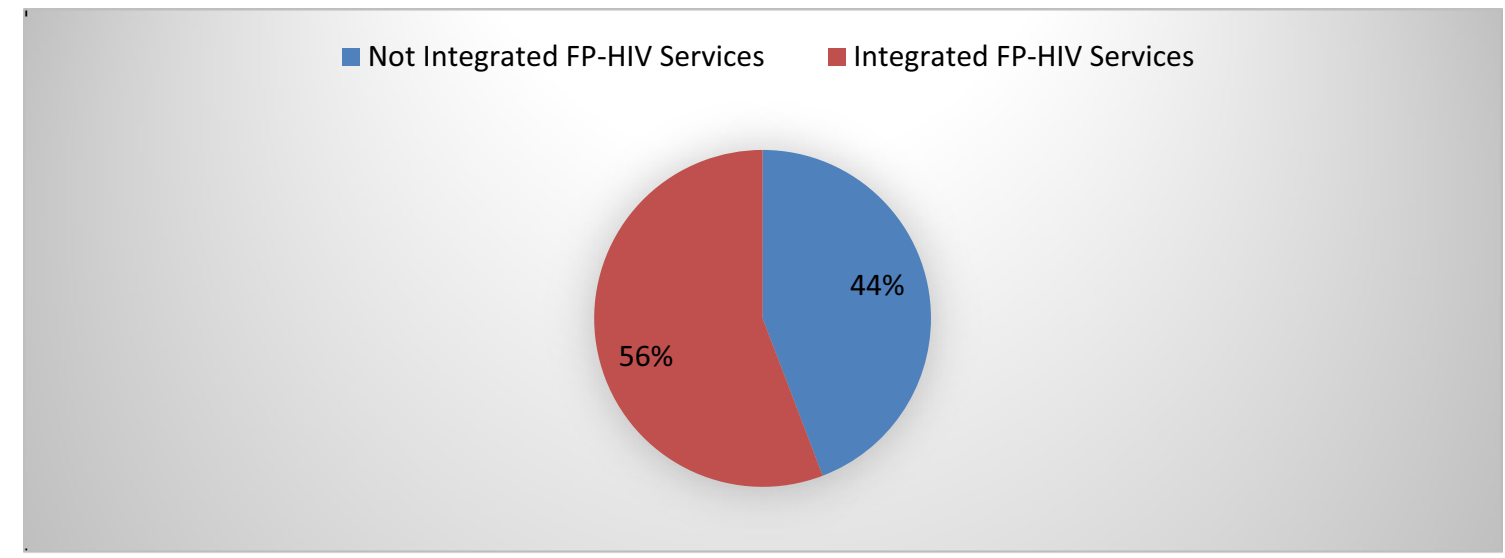

Fig. 1 Integration family planning/HIV services for women living with HIV attending ART clinics in Oromia, Ethiopia 2018 


\section{Current FP use cross tabulation Integration of FP-HIV services}

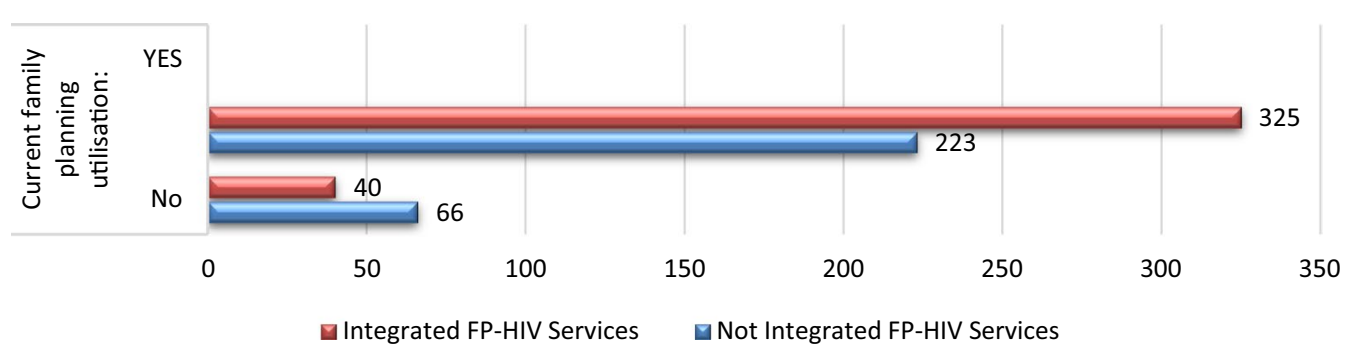

Fig. 2 Distribution of current family planning using cross tabulation

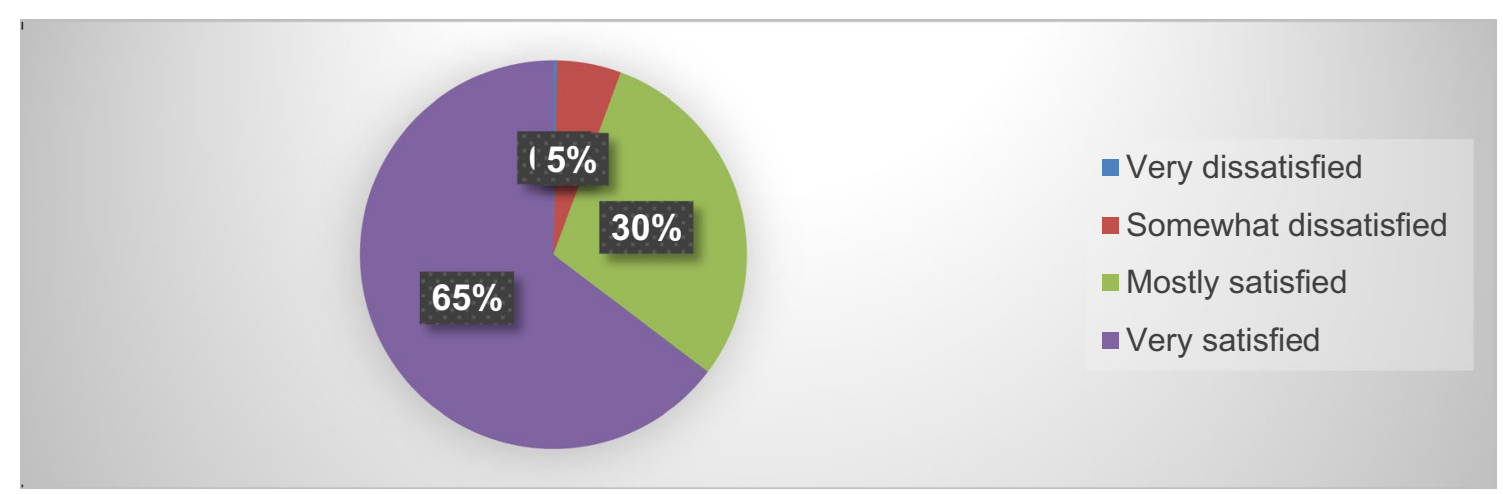

Fig. 3 Level of satisfaction on the utilisation of integration of family planning/HIV services in Oromia, Ethiopia, 2018

exit interview results revealed that more than 622 (95\%) respondents are very or mostly satisfied with the utilization of integrated family planning/HIV services.

In this study, almost all respondents $(n=635,97.1 \%)$ preferred integrated sexual reproductive health and HIV services at the same facility, from the same providers, and 622 (95\%) were very or mostly satisfied with the utilization of integrated family planning/HIV services.

\section{Factors associated with the integration of family planning/ HIV services}

Bivariate analysis was used primarily to check which variables had an individual associated with the dependent variable.

Variables that had significant association were identified based on an AOR with 95\%CI and p-value to fit into the final regression model.

Table 3 depicts variables associated with the integration of family planning/HIV services by multivariable logistic regression.

Table 3 shows the final regression model which indicates that $\mathrm{N}=654(\mathrm{p}<0.019)$, attended school (AOR 1.73, 95\% CI 1.09-2.73, $\mathrm{p}=0.004)$, had an occupational status with the government (AOR 5.16, 95\% CI 1.6715.94 and $\mathrm{p}<0.019$ ), merchant/private work (AOR 2.79, 95\% CI 1.18-6.58) compared to those who were unemployed $(\mathrm{p}<0.001)$, in urban residence (AOR 2.61, 95\% CI 1.47-4.62, $\mathrm{p}<0.000)$, discussed family planning with a healthcare provider (AOR 5.83, 95\% CI 3.07-11.06, $\mathrm{p}<0.009$ ), had fertility desire (AOR 1.804 , 95\% CI 1.156$2.82, \mathrm{p}<0.000$ ), were counselled on family planning (AOR 14.69, 95\% CI 9.36-23.07, $\mathrm{p}<0.023)$ had a recent CD4 cells $/ \mathrm{ml}^{3}$ of 501 and above (AOR 1.82, 95\% CI 1.0873.047). These factors were independently associated with increased integration of family planning/HIV services.

\section{Discussion}

This study determined the overall integration of FP-HIV services was $55.8 \%$ among reproductive-age women living with HIV with identified factors that affected the integration of family planning with HIV services were educational and occupational status, residence, discussion of family planning with healthcare providers, fertility desire, and CD4 counts. 
Table 3 Factors associated with Integration of family planning/HIV services at multivariable logistic regression (AOR, 95\% CI) in Oromia, Ethiopia 2018

\begin{tabular}{|c|c|c|c|c|c|}
\hline \multirow{2}{*}{\multicolumn{2}{|c|}{$\begin{array}{l}\text { Factors associated with Integration of family } \\
\text { planning/HIV services }\end{array}$}} & \multicolumn{2}{|c|}{ Integration of family planning/HIV services } & \multirow[t]{2}{*}{ COR $(95 \% \mathrm{Cl})$} & \multirow[t]{2}{*}{ AOR $(95 \% \mathrm{Cl})$} \\
\hline & & Yes & No & & \\
\hline \multicolumn{2}{|l|}{ Attended school: Yes } & $272(41.6)$ & $137(20.9)$ & $3.25(2.33-4.51)^{* * *}$ & $1.73(1.09-2.73)^{*}$ \\
\hline \multicolumn{2}{|l|}{ No } & $93(14.2)$ & $152(5.7)$ & $1: 00$ & $1: 00$ \\
\hline \multicolumn{2}{|l|}{ Occupational: Gov't } & $46(7.0)$ & $13(2.0)$ & $3.69(1.58-8.65)^{* *}$ & $5.16(1.67-15.94)^{* *}$ \\
\hline \multicolumn{2}{|l|}{ Merchant/private work } & $156(23.9)$ & $83(12.7)$ & $1.97(1.034-3.74)^{*}$ & $2.79(1.18-6.58)^{*}$ \\
\hline \multicolumn{2}{|l|}{ Housewife } & $125(19.1)$ & $131(20.0)$ & $0.998(0.53-1.88)$ & $1.31(0.57-3.00)$ \\
\hline \multicolumn{2}{|l|}{ Farmer } & $16(2.4)$ & $39(6.0)$ & $0.429(0.188-0.98)^{*}$ & $1.23(0.419-3.62)$ \\
\hline \multicolumn{2}{|l|}{ Unemployed } & $22(3.4)$ & $23(3.5)$ & $1: 00$ & $1: 00$ \\
\hline \multicolumn{2}{|l|}{ Residence: Urban } & $325(49.7)$ & $193(29.5)$ & $4.04(2.68-6.087)^{* * *}$ & $2.61(1.47-4.62)^{* * *}$ \\
\hline \multicolumn{2}{|l|}{ Rural } & $40(6.1)$ & $96(14.7)$ & $1: 00$ & $1: 00$ \\
\hline \multirow{2}{*}{$\begin{array}{l}\text { Discussed with health- } \\
\text { care provider }\end{array}$} & Yes & $344(52.6)$ & $199(30.4)$ & $7.4(4.47-12.29)^{* * *}$ & $5.83(3.07-11.06)^{* * *}$ \\
\hline & No & $21(3.2)$ & $90(13.8)$ & $1: 00$ & $1: 00$ \\
\hline \multirow[t]{2}{*}{ Fertility desire } & Yes & $212(32.4)$ & $112(17.1)$ & $1: 00$ & $1: 00$ \\
\hline & No & $153(23.4)$ & $177(27.1)$ & $2.19(1.598-3.0)^{* * *}$ & $1.804(1.156-2.82)^{* * *}$ \\
\hline \multirow{2}{*}{$\begin{array}{l}\text { Family planning Coun- } \\
\text { selled }\end{array}$} & Yes & $291(44.5)$ & $64(9.8)$ & $13.8(9.48-20.16)^{* * *}$ & $14.69(9.36-23.1)^{* * *}$ \\
\hline & No & $74(11.3)$ & $225(34.4)$ & 1.00 & $1: 00$ \\
\hline \multirow{3}{*}{$\begin{array}{l}\text { Recent CD4 cells } / \mathrm{ml}^{3} \\
\text { count }\end{array}$} & $<=350$ cells $/ \mathrm{ml}^{3}$ & $72(11.0)$ & $92(14.1)$ & $1: 00$ & $1: 00$ \\
\hline & 351 to 500 cells $/ \mathrm{ml}^{3}$ & $95(14.1)$ & $65(9.9)$ & $1.87(1.2-2.90)^{* *}$ & $1.57(0.867-2.83)$ \\
\hline & $>=501$ cells $/ \mathrm{ml}^{3}$ & $198(30.3)$ & $132(20.2)$ & $1.92(1.31-2.80)^{* * *}$ & $1.82(1.087-3.047)^{*}$ \\
\hline
\end{tabular}

Cl confidence interval, $A O R$ adjusted, COR crude odd

*** $\mathrm{p}<0.001,{ }^{* *} \mathrm{p}<0.01,{ }^{*} \mathrm{p}<0.05$

The socioeconomic characteristics of the respondents as summarised in Table 1 are not different from the socioeconomic profile of Ethiopia. For example, in the general population of the same region, Christian denominations dominate and represent $65 \%$ of the population, $79.2 \%$ resided in urban areas, and the largest ethnic group is Oromo, followed by Amhara which represent 64\% of the population [9]. The results are also similar in terms of the proportion of women who are currently married or living together with a partner $(65 \%)$ in the general population [9].

\section{Integration of family planning services with HIV treatment in Oromia}

The study conducted by Bradley et al. [14] on VCT and family planning service integration in Ethiopia showed that counselors jointly offered HIV and family planning services with many repeat family planning clients. These health facilities attracted both standard $\mathrm{MNCH}$ clients [14]. On the integration of family planning services with HIV and related factors among those who came for VCT, the study established that the services offered were limited to information sharing on family planning methods and ARTs as well as referrals only.
The study by Bradley et al. [14] could not establish any integration of family planning services with HIV and related factors (family planning-HIV integration services) in Ethiopia in general, nor in Oromia in particular. This thesis gives a more comprehensive representation of the integration of family planning services with HIV services and its relationship with other selected factors in Oromia, hence determining the level of integration with sexual reproductive health, family planning, PMTC, and ART services. The integration includes a combination of training offered to service providers, supervision, and services provided by healthcare providers.

As far as the integration of family planning and HIV services is concerned, the study revealed that the ART clinics provided both ART drugs and contraceptive methods in ART clinics, of which 93.7\% were condoms, $90.2 \%$ were injectable, and $82.3 \%$ were oral contraceptives as chosen methods available during the study period. These findings were supported by a systematic review by O'Reilly et al. [15], who claim that concerted efforts on the provision of information and support for family planning use, coupled with ready access to a wide range of contraceptive methods, seemed to be most effective in increasing family planning utilization. 
The proportion of contraceptive information that was provided and utilization of the ART clinics was higher in this study, compared to a study conducted in Ghana. That study reported that $74 \%$ of women living with HIV had received information on contraception, $42.6 \%$ of participants and/or their partners were using a contraceptive method, and $79.6 \%$ used condoms [16]. The differences may be due to sociodemographic factors and the different healthcare systems in the two countries. For example, the training modules of family planning and HIV services were integrated in Ethiopia in line with an emphasis at the global level on SDGs. These strongly recommend the integration of sexual reproductive health services with HIV services [3]. One can conclude that the integration of family planning/HIV services in the Oromia Region, Ethiopia is more comprehensive as it ranged from counseling on available family planning services to the provision of injectable contraceptive methods, oral contraceptive pills, and condoms in the ART clinics. Integration also includes referring women of reproductive age for consultation on available long-acting and permanent methods on family planning within the same facility.

As mentioned, this study showed that $93.7 \%$ of respondents used condoms, $90.2 \%$ injectable, and $82.3 \%$ oral contraceptives. Moreover, $54.3 \%$ received family planning counseling on available methods. The contraceptive methods were provided by trained health professionals in the waiting room. A further revelation in this study is that $77.4 \%$ of respondents received family planning counseling about the efficacy of each method and the clients were referred to a family planning unit within the same facility for consultation on available long-acting and permanent methods, of which $88.8 \%$ received an implant, 61.3\% IUDs and 29.1\% tubal ligation.

This study's findings are similar to those of the study conducted in Lusaka by [17] which revealed that $80 \%$ of respondents accessed family planning services in ART clinics, and 99\% reported having used modern contraception, of which $60 \%$ used condoms, $15 \%$ injectable contraception, and $11 \%$ oral contraceptive pills. This result indicates that healthcare providers should offer a standardized family planning/HIV service on all the components of essential sexual reproductive health services with routine ART drug refilling and therapy in public health facilities before they are appointed for HIV services alone [18].

This study identified that $50 \%$ of current family planning users used integrated family planning/HIV services versus $6.1 \%$ who did not use integrated services. Further, $48.3 \%$ of those who had their need for family planning met were using integrated family planning/HIV services versus $32.7 \%$ who were not using integrated services. These findings were supported by a previous study conducted in Kenya which showed that $73 \%$ of women were more likely to use family planning if it was offered at the HIV clinic, and $45 \%$ reported to be using a barrier or natural method currently [19]. Therefore, the integrated family planning/HIV services in the ART clinics of Oromia Region, Ethiopia, should include counseling on available family planning services such as injectable contraceptive methods, pills, and condoms in the ART clinics. Moreover, women of reproductive age should be referred to the family planning room within the same facility for consultation on available long-acting and permanent contraceptive methods.

\section{Factors affecting the integration of family planning services with HIV services}

This study identified the level of education, occupational status, residence, discussions with healthcare providers regarding family planning, fertility desire, having received counseling on family planning, and recent CD4 cells $/ \mathrm{ml}^{3}$ as factors that increase the necessity for integrated family planning/HIV services. These findings are in line with previous studies conducted in Rakai by Brahmbhatt et al. [20] and a study conducted in Zambia by Hancock et al. [17]. Thus, it is critical to consider these identified factors for the implementation of integrated family planning/ HIV services for women of reproductive age living with HIV attending ART/PMTC follow-up programs.

A previous study by Newmann et al. [19] identified factors that contributed to minimal integrated services as changes in contraceptive use and perception of others as being infertile, while this study did not support this finding. This may be because in this study almost all (97.1\%) respondents preferred integrated sexual reproductive health and HIV services at the same facility or site. Additionally, almost all respondents, that is, $96.9 \%$, preferred to receive sexual reproductive health with HIV services from the same providers. Another possible explanation may since more than $95 \%$ of respondents were satisfied with the utilization of integrated family planning/HIV services, which was confirmed during an exit interview at the time of the study.

\section{Limitation of the study}

Though the problem of recall bias was minimized by conducting exit interviews; the current study is not free of social desirability bias in which some mothers may report the service as positive experiences while they are in the health facilities. As a strength, the study tried to cover a large number of health facilities including health centers and large sample size. 


\section{Conclusion}

This study established that overall; the integration of family planning/HIV services was relatively moderate among women of reproductive age living with HIV. The identified factors affected integration of family planning with HIV services were educational and occupational status, residence, discussion of family planning with healthcare providers, fertility desire, and CD4 counts (Additional file 1).

\section{Recommendation}

- Engage women in the planning, implementation, and evaluation of the integrated family planning/HIV services to empower them to decide on their choices regarding family planning/HIV services.

- Promote the integrated family planning/HIV services using the mass media with local context in different languages.

- Develop and distribute tailored IEC/BCC materials (posters, leaflets, flyers, brochures, magazines) related to integrated family planning and HIV service to the community by using local languages for women of reproductive age and people living with HIV.

- FMOH and other stakeholders should renovate and equip health facilities with trained, motivated, respectful, caring, and compassionate healthcare providers to offer integrated reproductive health services-including family planning/HIV services-at single visits based on their needs.

- Healthcare providers (nurses, health officers, midwives, and physicians) should strengthen the provision of comprehensive health education throughout the sexual reproductive health services-including family planning and chronic care for HIV-in the waiting room area to increase awareness on the integrated people-centered family planning/HIV services in Oromia Region health care facilities.

- Provide quality counseling to improve the knowledge of reproductive-aged and empowered women by service providers on the integrated family planning/HIV services.

- The integration of family planning services with ART and PMTCT has a great contribution in achieving the end of new pediatric HIV infection. It is recognized in relevant policy statements, yet few PMTCT programs have increased access to contraception for HIV-infected women and couples who do not wish to become pregnant.

- A shift in how ART/PMTCT programs are conceptualized, implemented, and evaluated is needed to bet- ter address the family needs of HIV-infected women and accelerate progress towards ending new pediatric HIV infections.

\section{Abbreviations}

AIDS: Acquired Immune Deficiency Syndrome; ART: Antiretroviral therapy; AOR: Adjusted odd ratio; CSA: Central Statistical Agency; Cl: Confidence interval; COR: Crude odd ratio; EDHS: Ethiopian Demographic Health Survey; FHI: Family Health International; FMOH: Federal Ministry of Health; HIV: Human immuno-deficiency virus; IUDs: Intra uterine devices; OR: Odds ratio; ORHB: Oromia Regional Health Bureau; PMTCT: Prevention of mother-to-child transmission; SDGs: Sustainable development goals; STIs: Sexually transmitted infections; UNAIDS: United Nations Programme on HIV/AIDS; UNICEF: United Nations International Children's Emergency Fund; UNISA: University of South Africa; USAID: United States Agency for International Development; VCT: Voluntary HIV counseling and testing; WHO: World Health Organization.

\section{Supplementary Information}

The online version contains supplementary material available at https://doi. org/10.1186/s12978-021-01157-0.

Additional file 1. German abstract.

\section{Acknowledgements}

We want to 'acknowledge the University of South Africa (UNISA) for giving us this opportunity. Our deepest gratitude goes to study participants, Ambo University, College of medicine and health sciences, Oromia Region Health Bureau, special zone surroundings of Finfinne Health office, supervisors, and data collectors for their support. Finally, we would like to express my gratitude to all participants who volunteered participated in the study.

\section{Authors' contributions}

All authors made substantial contributions to conception and design, acquisition of data, or analysis and interpretation of data; took part in drafting the article or revising it critically for important intellectual content; gave final approval of the version to be published; and agree to be accountable for all aspects of the work. Both authors read and approved the final manuscript.

\section{Funding}

Funding for this study was obtained from Ambo University. The university had no role in the design of the study and collection, analysis, and interpretation of data.

\section{Availability of data and materials}

Datasets used in the current study are available from the corresponding author upon reasonable request.

\section{Declarations}

\section{Ethics approval and consent to participate}

The researcher submitted a letter seeking ethical approval and permission to conduct the study from the Research and Technology Transfer Core-process of the Oromia regional health Bureau (ORHB) and received approval (Ref. No. BEFO/HBT64/18/2564). Thereafter, a letter of permission to conduct this research was also obtained from the ORHB who requested support for the researcher from each study site to facilitate the data collection process (Ref. No. BEFO/HBT64/18/2569). Informed consent from each study participant was obtained after the nature of the study was fully explained in their local languages as was attached in the questionnaire. The respondents' right to refuse or withdraw from the study at any stage was respected. Information collected from respondents was kept confidential, and the collected information was stored in a locked space, in a file without the name of the study respondent 
(anonymously), but codes were assigned for each respondent and have not been disclosed to others except the principal investigators. Scientific integrity was ensured by avoiding plagiarism, being honest in reporting on the findings, and accurately citing all consulted sources. A formal letter of cooperation was written to all selected Health institutions. Written informed consent was obtained from study participants after fully explaining the nature of the study in their local languages as is attached in the questionnaire. The collected information was kept confidential without the name of the study participants.

\section{Consent for publication}

Not applicable.

\section{Competing interests}

Authors declared that they have no competing interest.

\section{Author details}

'Department of Health Studies, College of Human Science, University of South Africa, Pretoria, South Africa. ${ }^{2}$ St. Paul's Hospital Millennium Medical College, Addis Ababa, Ethiopia. ${ }^{3}$ Department of Public Health, College of Human Science, University of South Africa, Pretoria, South Africa.

Received: 21 December 2020 Accepted: 13 May 2021

Published online: 22 May 2021

\section{References}

1. Atun R, Lazarus JV, Van Damme W, Coker R. Interactions between critical health system functions and HIV/AIDS, tuberculosis, and malaria programs. Health Policy Plan. 2010;25:i1-3.

2. UNAIDS. UNAIDS terminology guidelines. Geneva, Swaziland: UNAIDS; 2015.

3. World Health Organization. 2016. Consolidated guidelines on the use of antiretroviral drugs for treating and preventing HIV infection: recommendations for a public health approach. $2^{\text {nd }}$ edn. Geneva: WHO. http:// apps.who.int/iris/bitstream/10665/208825/1/9789241549684_eng.pdf. Accessed 6 Jun 2019.

4. Sustainable development goals is issued as document A/68/970. http:// undocs.org/A/68/970. Accessed 13 May 2016.

5. Kendall T, Danel I. Research and evaluation agenda for HIV and maternal health in sub-Saharan Africa. Boston, MA: Harvard School of Public Health; 2014

6. Pack RP, Li X, Stanton BF, Cottrell LA. 2011. Psychosocial correlates of dual methods for contraception and STI protection in urban adolescents. ISRN Obstetr Gynecol. 2011.

7. Darroch JE, Singh S. Trends in contraceptive need and use in developing countries in 2003, 2008, and 2012: an analysis of national surveys. Lancet. 2013;381(9879):1756-62.

8. Sarnquist CC, Rahangdale L, Maldonado Y. Reproductive health and family planning need among HIV-infected women in Sub-Saharan Africa. Curr HIV Res. 2013;11(2):160-8.
9. Central Statistical Agency. 2016. Ethiopia demographic and health survey 2016: Key indicators report. Addis Ababa, Ethiopia, and Rockville, Maryland, USA: CSA and ICF.

10. Ahmed S, Li Q, Liu L, Tsui AO. Maternal deaths averted by contraceptive use: an analysis of 172 countries. Lancet. 2012;380(9837):111-25.

11. Office Finfinne Special Zone. 2018. Sociodemographic data of Finfine special zone. Unpublished source.

12. Scholl E, Cothran D. 2011. Integrating family planning and HIV services. programs in Kenya and Ethiopia lead the way. Case study series. Arlington, VA: USAID's AIDS Support and Technical Assistance Resources, AIDSTAR-One, Task Order 1.

13. Hamilton, LC. 2012. Statistics with stata: Version 12. Boston, MA:Cengage Learning.

14. Bradley H, Bedada A, Tsui A, Brahmbhatt H, Gillespie D, Kidanu A. HIV and family planning service integration and voluntary HIV counseling and testing client composition in Ethiopia. AIDS Care. 2008;20(1):61-71.

15. O'Reilly KR, Kennedy CE, Fonner VA, Sweat MD. Family planning counseling for women living with HIV: a systematic review of the evidence of effectiveness on contraceptive uptake and pregnancy incidence, 1990 to 2011. BMC Public Health. 2013;13(1):935.

16. Laryea DO, Amoako YA, Spangenberg K, Frimpong E, Kyei-Ansong J. Contraceptive use and unmet need for family planning among HIV positive women on antiretroviral therapy in Kumasi, Ghana. BMC Womens Health. 2014;14(1):126.

17. Hancock NL, Chibwesha CJ, Bosomprah S, Newman J, Mubiana-Mbewe M, Sitali ES, Chi BH. Contraceptive use among HIV-infected women and men receiving antiretroviral therapy in Lusaka, Zambia: a cross-sectional survey. BMC Public Health. 2016;16(1):392.

18. Church K, Mayhew SH. Integration of STI and HIV prevention, care, and treatment into family planning services: a review of the literature. Stud Fam Plann. 2009;40(3):171-86.

19. Newmann SJ, Grossman D, Blat C, Onono M, Steinfeld R, Bukusi EA, Cohen CR. Does integrating family planning into HIV care and treatment impact intention to use contraception? Patient perspectives from HIVinfected individuals in Nyanza Province, Kenya. Int J Gynecol Obstetr. 2013;123:e16-23.

20. Brahmbhatt H, Makumbi F, Lutalo T, Sekasanvu J, Serwadda D, Wawer MJ, Gray $\mathrm{RH}$. A longitudinal study of correlates of modern contraceptive use and impact of HIV care programs among HIV concordant and serodiscordant couples in Rakai, Uganda. J Fam Plann Reprod Health Care. 2014;40(3):208-16.

\section{Publisher's Note}

Springer Nature remains neutral with regard to jurisdictional claims in published maps and institutional affiliations.
Ready to submit your research? Choose BMC and benefit from:

- fast, convenient online submission

- thorough peer review by experienced researchers in your field

- rapid publication on acceptance

- support for research data, including large and complex data types

- gold Open Access which fosters wider collaboration and increased citations

- maximum visibility for your research: over 100M website views per year

At BMC, research is always in progress.

Learn more biomedcentral.com/submissions 